\title{
Shear Resisting Mechanism and Shear Strength Equation for Sandwich Beams
}

\author{
Ataur Rahman ${ }^{1} \&$ Tamon Ueda ${ }^{1}$ \\ ${ }^{1}$ Hokkaido University, Sapporo, Hokkaido, Japan \\ Correspondance: Room No. 210, Department of Civil Engineering, Khulna University of Eng. \& Tech. (KUET), \\ Khulna 9203, Bangladesh. Cell: 88-017-1408-7309. E-mail: ataur107@yahoo.com
}

Received: November 16, 2017

Accepted: December 17, 2017

Online Published: January 31, 2018

doi:10.5539/jmsr.v7n2p1

URL: https://doi.org/10.5539/jmsr.v7n2p1

\begin{abstract}
The aim of this study is to eliminate the limitation of existing shear design equations and to establish a complete set of rational as well as computationally efficient shear design equations. On this goal, a macro physical model, based on 2D nonlinear FEM analysis, for both open and full sandwich beams are developed which can clearly demostrate the contributions of different parts of the sandwich beam in resisting shear force. The proposed model also shows a satisfactory correlation between the experimental and the analytical results. A series of analytical specimens in connection with experimental one are analyzed by engaging a 2D-FEM program and a complete set of shear strength equations are derived with the help of that proposed shear resisting model. The equations for full sandwich beam show a good agreement with experimental and analytical results, whereas equations for open sandwich beam require further investigation to increase their level of accuracy and are not presented here.
\end{abstract}

Keywords: full and open sandwich beams, finite element analysis, shear resisting model

\section{Introduction}

With the advancement of innovative design of composite structures for civil engineering construction, steel-concrete sandwich structures (Figure 1) have added a new dimension for the contentment of structural designer, when construction restrictions and safely become a vital issue than construction cost. Steel - concrete composite beam, more specifically, open and full (box) sandwich beams, are such a new solution to construct structures like bridge deck \& girder, submerged box tunnel etc. Most of these heavy duty structures sustain a substantially high amount of dead/live load than the traditional RC structures. Sometime sudden impulsive load on a small area may cause shear failure which is so catastrophic in nature that it does not give sufficient warning prior to failure with the primary crushing of concrete as a consequence rather than yielding of flexural steel. In this case, it is crucial to visualize the shear resisting mechanism and eventually evaluate shear strength with good accuracy.

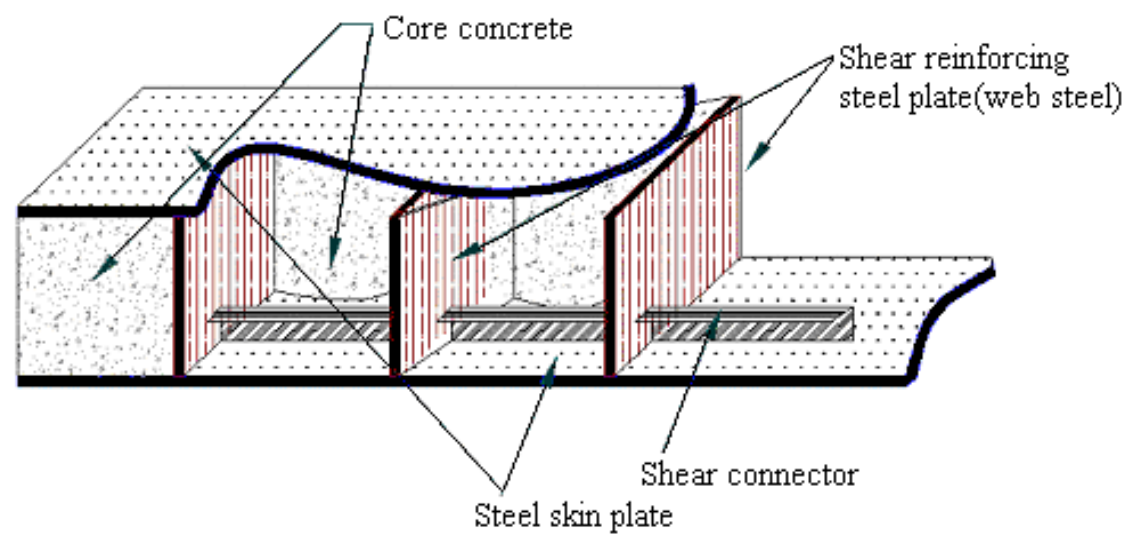

Figure 1. A typical sandwich member 


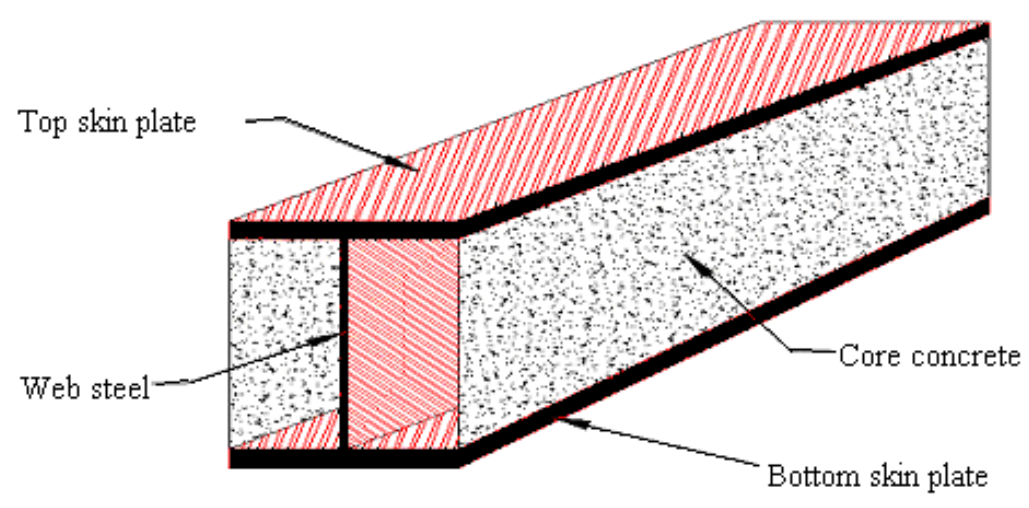

Figure 2. A typical full sandwich beam

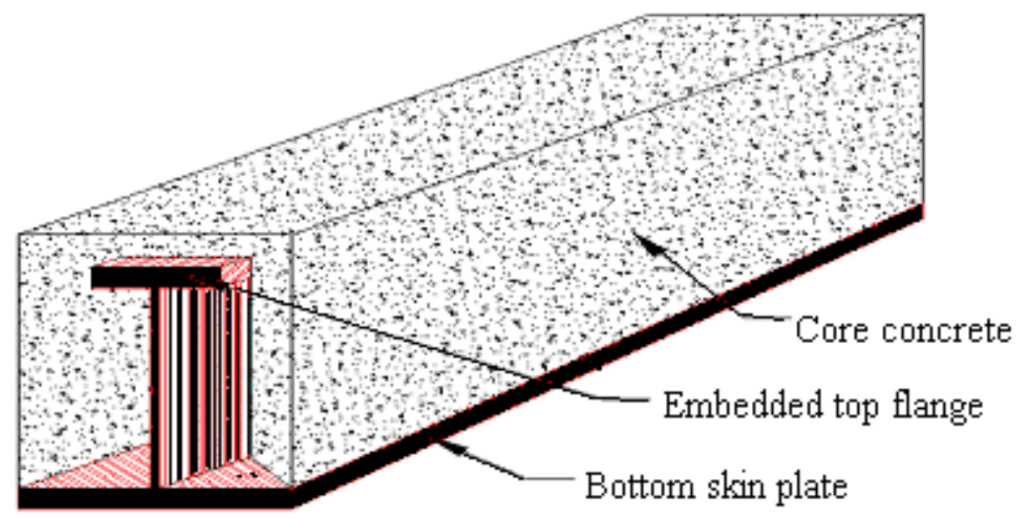

Figure 3. A typical open sandwich beam

Unlikely to RC beams, normally sandwich beams are designed with a larger amount of steel in a fashion of skin plate and embedded web plate (Figure 2 and Figure 3).Without concrete most of the sandwich beams look like typical steel I-beam.

Shear compression failure of surrounded concrete is very common where shear span to depth ratio is no too high to lead a flexural failure. Due to the confinement of concrete by steel skin plate sandwich beam shows quite ductile failure behavior than explosive type of shear tension failure. The conventional method of shear design for RC member cannot be applied directly to sandwich member due to the difference in steel reinforcement configuration and arrangement.

In sandwich beam, shear connector is provided between steel-concrete interface to curb the direct shear failure at this predetermined plane of weakness.

\section{Method to Predict Shear Strength}

Considering the contemporary research on sandwich beam, there are two basic approaches,

Conventional approach

Numerical approach

\subsection{Conventional Approach}

Most of the past research to predict the shear strength of sandwich beam based on three popular analogies.

Classical beam theory

Truss analogy (compression field theory)

Tied-arch mechanism 


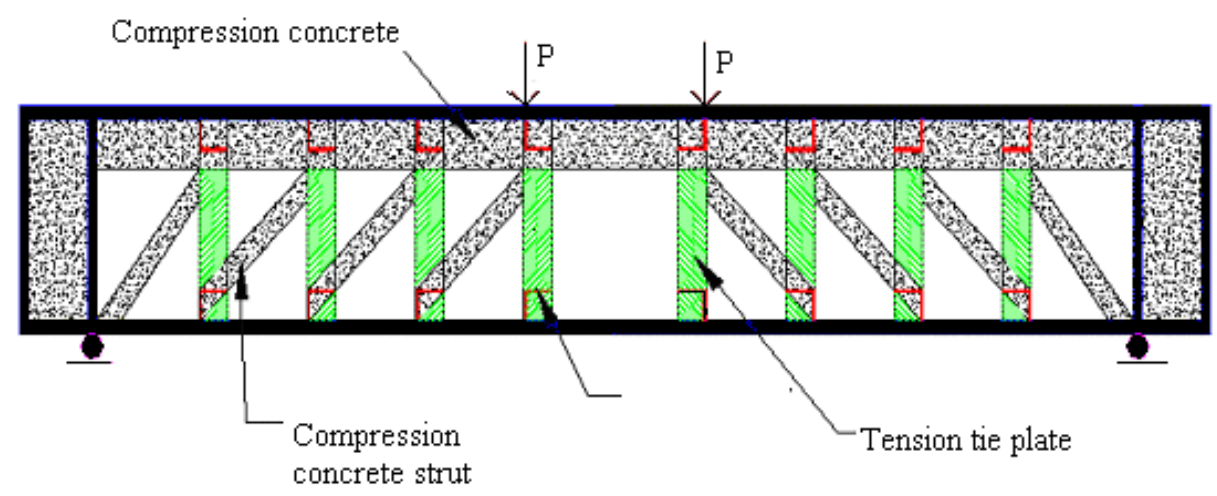

Figure 4. Truss action in a full sandwich beam

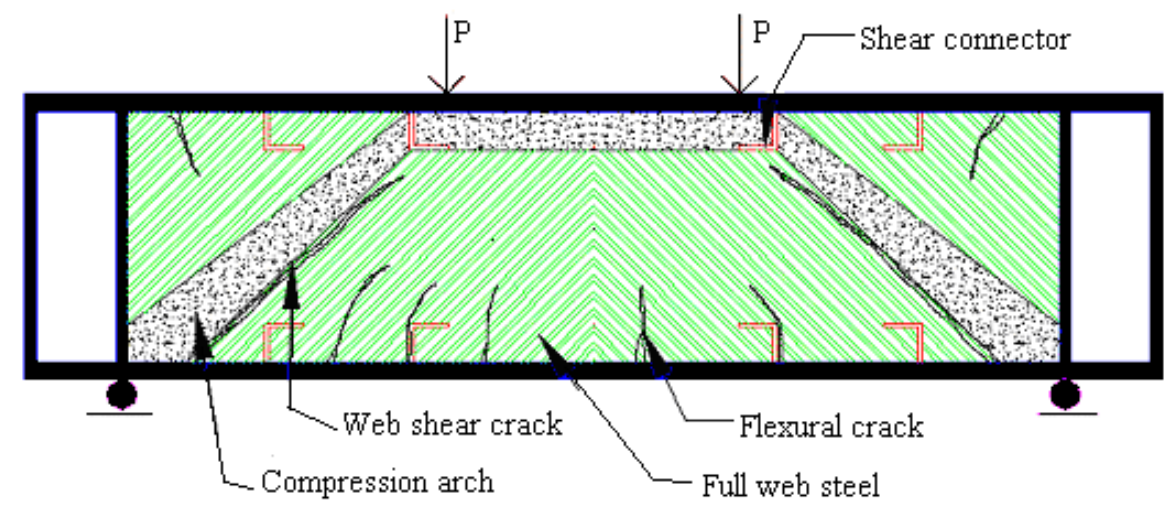

Figure 5. Tied-arch action in a full sandwich beam

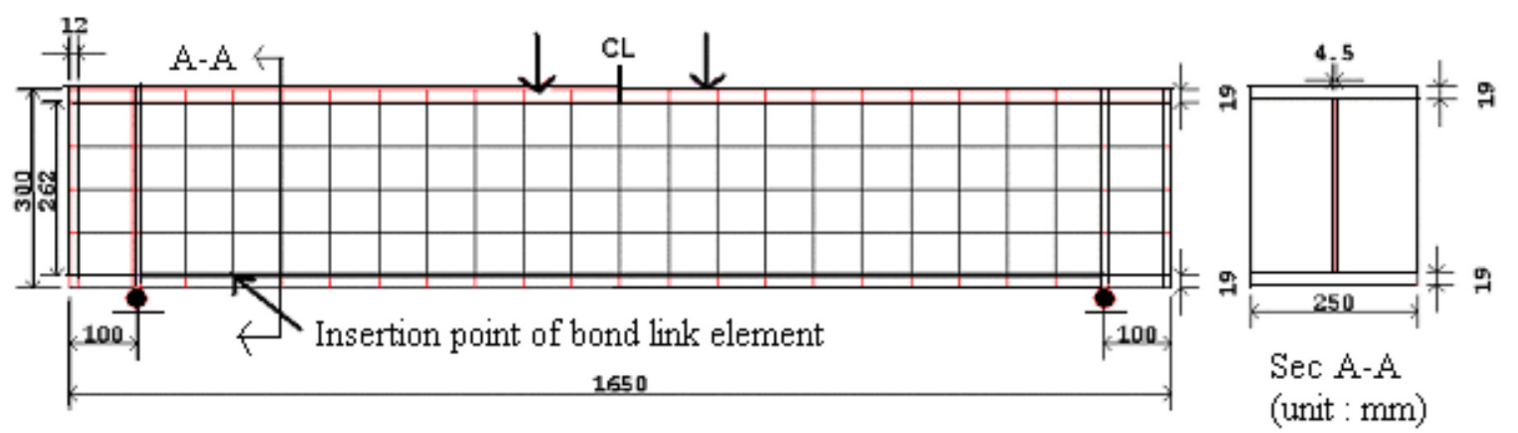

Figure 6. Four-point loading condition for both experimental and analytical specimens

Among the above three, truss mechanism (Figure 4) is the simplest one where shear resistance by concrete in compression zone and aggregate interlocking force along the diagonal shear crack is totally ignored. Only the diagonal compression force is considered as concrete contribution to shear resistance (Nares, 1991). Tied-arch mechanism (Figure 5) is quite applicable for beam with a shear span to depth ratio is less than 2. Beam of this category commonly known as deep beam. Because of this proportions, they are likely to have strength controlled by shear and have a higher shear capacity over usual beams of $a / d$ greater than 2 .

\subsection{Numerical Approach}

No doubt finite element method (FEM) is one of the powerful numerical techniques by which any complex physical process can be simulated precisely. In this study none of the above analogies is directly applied, rather macro physical model for shear resisting mechanism will be presented based on a series of nu-merical experimentation with FEM simulation. 


\section{Experimental Program}

Experimental study was conducted as a reference for the analytical procedure. Most of the analytical spec-imens are kept similar to that of the experimental one to ensure that analytical result is going on the same line of experimental one. On this goal a good number of both full and open type sandwich specimens are tested as shown in Table 1. In this Table expBN1 to expBN5 are full type and expH327 to expL457 are open type sandwich specimens. The experimental setup is in accordance with Figure 6. For detail information please see Rahman (2002).

Table 1. Experimental specimens

\begin{tabular}{|c|c|c|c|c|c|c|}
\hline \multirow[b]{2}{*}{ Specimen } & \multirow[b]{2}{*}{$\begin{array}{c}f_{c}^{\prime} \\
\mathrm{MPa}\end{array}$} & \multicolumn{2}{|c|}{ Full web } & \multicolumn{3}{|c|}{ Shear strength } \\
\hline & & $\begin{array}{c}f_{w y} \\
\mathrm{MPa}\end{array}$ & $\begin{array}{l}P_{w} \\
\% \\
\end{array}$ & $\begin{array}{c}\text { Failure } \\
\text { mode }\end{array}$ & $\begin{array}{l}\text { Test } \\
\mathrm{kN}\end{array}$ & $\begin{array}{c}\text { FEM } \\
\mathrm{kN}\end{array}$ \\
\hline expBN1 & 24.4 & - & 0 & $\mathrm{SC}^{*}$ & 291 & 248 \\
\hline $\operatorname{expBN} 2$ & 26.0 & 319 & 1.20 & $\mathrm{SC}$ & 603 & 555 \\
\hline $\operatorname{expBN3}$ & 24.7 & 324 & 1.80 & $\mathrm{SC}$ & 722 & 654 \\
\hline $\operatorname{expBN4}$ & 24.4 & 342 & 2.40 & $\mathrm{SC}$ & 796 & 755 \\
\hline $\operatorname{expBN5}$ & 22.3 & 342 & 1.20 & $\mathrm{SC}$ & 554 & 483 \\
\hline expH327 & 36.0 & 250 & 2.13 & $\mathrm{SC}$ & 330 & 300 \\
\hline expH457 & 34.3 & 249 & 3.00 & $\mathrm{SC}$ & 381 & 351 \\
\hline expH607 & 33.5 & 249 & 4.00 & $\mathrm{SC}$ & 426 & 361 \\
\hline expH453 & 33.9 & 249 & 3.00 & $\mathrm{SC}$ & 344 & 318 \\
\hline expL457 & 36.9 & 249 & 3.00 & $\mathrm{SC}$ & 337 & 320 \\
\hline
\end{tabular}

\section{Analytical Program}

The aim of this study is to develop rational shear strength equations with a broad spectrum or band-width. On this regard a series of beams are analyzed with different variable parameters. They are as fol-lows.

Shear span to depth ratio $(a / d)$

Compressive strength of concrete $\left(f_{c}^{\prime}\right)$

Percentage of web steel $\left(P_{w}\right)$

Percentage of flexural Steel $\left(P_{s}\right)$

Yield strength of web steel $\left(f_{w y}\right)$

\section{Shear Resisting Model}

The shear resisting model is divided into two parts

Concrete model

Steel model

\subsection{Concrete Model}

Types of cracks in a sandwich beam are very similar to those in a usual RC beam (Figure 7) as shown in Figure 8. But it is quite uncertain to know the exact location of crack which causes the beam to fail along the crack path.

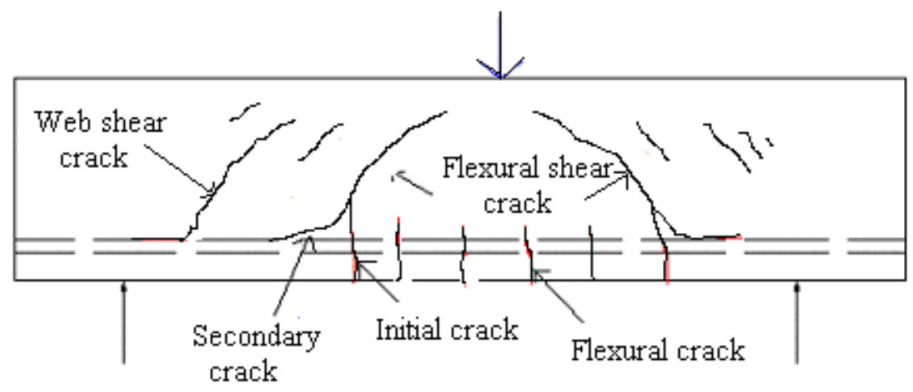

Figure 7. Different type of cracks in RC beam 


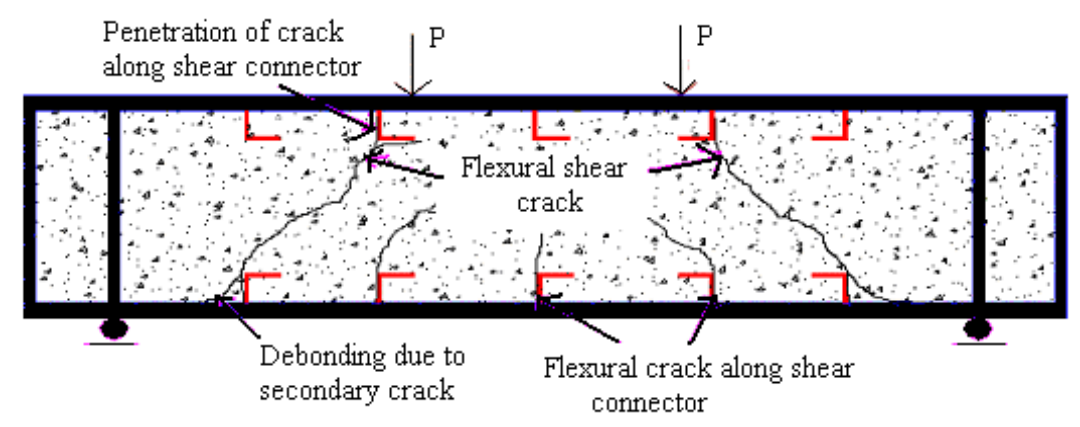

Figure 8. Formation of crack in full sandwich beam

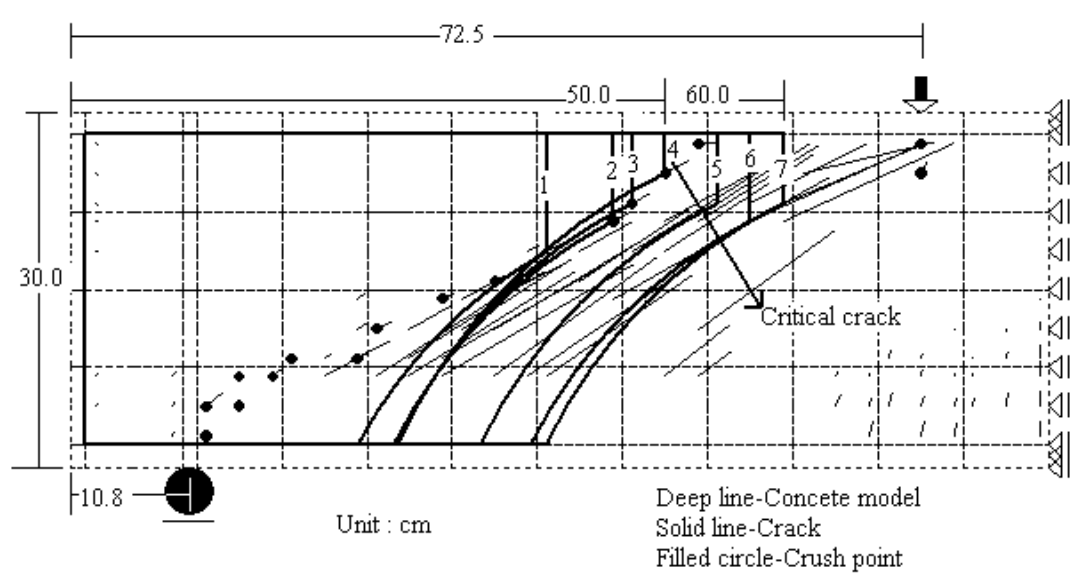

Figure 9. Location of critical crack in concrete model

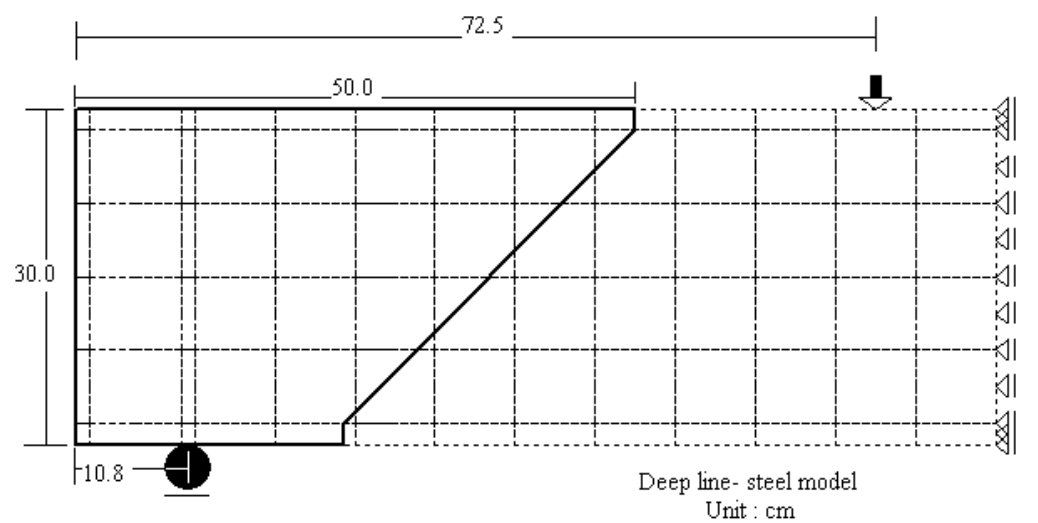

Figure 10. Steel model along the critical crack path

So in this model (Figure 9) the follow-ing assumptions are considered to locate the critical or main crack.

The crack with a minimum depth of compression zone close to loading point should be a critical one. Because this crack has a maximum depth of penetration into the compression zone. And this compression zone experience maximum shear stress.

Near the neutral axis the critical crack should have an inclination angle of $45^{\circ}$.

A circular arc with a 450 chord inclination from the beneath of compression zone to the extreme bottom fiber of the concrete is the cracking path of the critical crack.

For open sandwich beam, in no case the crack can penetrate beyond the top flange.

Throughout the loading history, a particular crack at a particular location will not necessarily remain same due to internal stress redistribution and rearrangement. 


\subsection{Steel Model}

Compare to the concrete model, steel model is rather simple. Upon selecting the critical crack, the steel model traces the same path of concrete in linear way to produce minimum area with a maximum stress (Figure 10).

\section{Shear Strength Equations}

A complete set of empirical equations is developed considering the corresponding affecting parameter(s) mentioned in section 4. The stresses are:

Stress in compression zone, $S c z$ (Eq. 1)

Stress at cracked zone, $\mathrm{Si}$ (Eq. 2)

Stress at top flange, $S_{t f}$ (Eq. 3)

Stress at web steel, $S_{w e b}$ (Eq. 4)

Stress at bottom flange, $S_{b f}$ (Eq. 5)

Here all the stresses are in MPa.

The empirical equations are:

$$
\begin{gathered}
S_{c z}=0.2 f_{c}^{\prime}+3 \log P_{s}+3 \log P_{w}-0.5 \frac{a}{d} \text { and } \geq 0.50 \\
S_{i}=3.3 \log P w+0.03 f_{c}^{\prime}-2.8 \log \left(\frac{a}{d}\right)+5 \\
S_{t f}=6 \log P_{w}+0.1 f_{c}^{\prime}-5.5 \log \left(\frac{a}{d}\right)+2.2 \quad \text { and } \geq 0.20 \\
S_{w e b}=60 \log P_{w}+12 \log P_{s}-0.75 f_{c}^{\prime}+0.50 f_{w y}+40 \log \left(\frac{a}{d}\right)-45 \quad \text { and } \geq 25 \\
S_{b f}=4.5 \log P_{w}+0.2 \log P_{s}+1.07 e^{0.04 f_{c}^{\prime}}+3.5 \log \left(\frac{a}{d}\right)-0.25 \quad \text { and } \geq 0.25
\end{gathered}
$$

Depth of compression zone, $Y_{\text {com }}$ is calculated by Equation 6 below:

$$
Y_{\text {com }}=d\left[-0.21 \log \left(\frac{a}{d}\right)+0.25\right] \text { and } \geq 0.1 d
$$

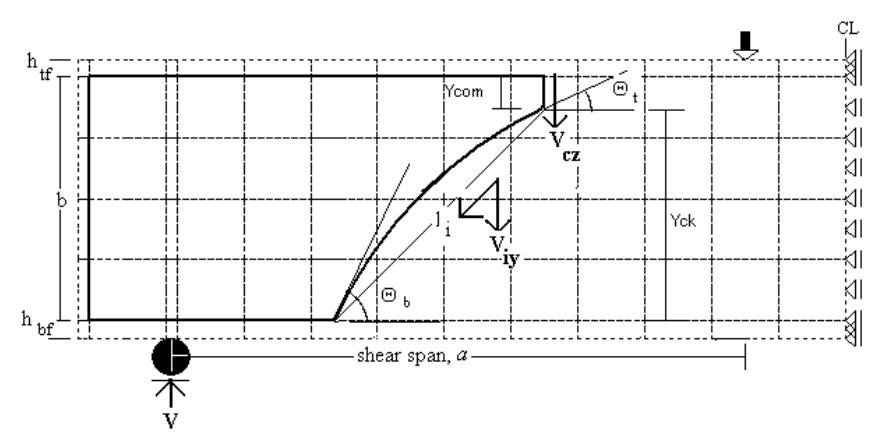

Figure 11. Concrete contribution in shear

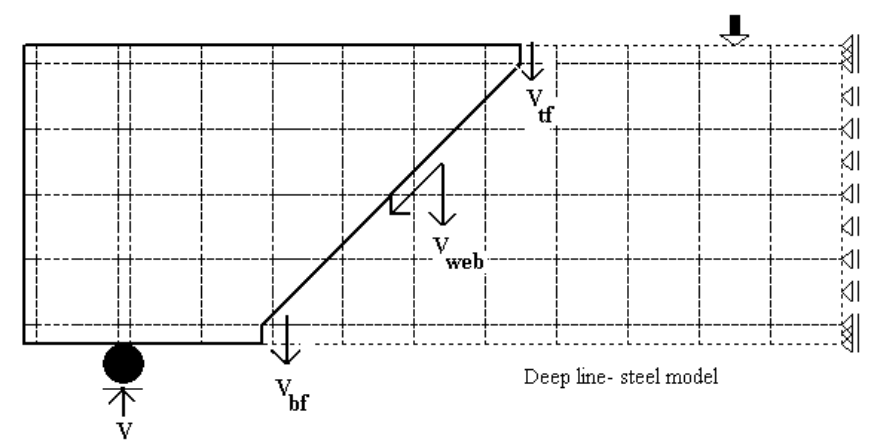

Figure 12. Steel contribution in shear 
Depth of cracked concrete, $Y_{c k}$ is given by Equation 7 below:

$$
Y_{c k}=h_{w e b}-Y_{c o m}
$$

Where, $h_{\text {web }}=$ hight of the web steel

$$
=h-h_{t f}-h_{b f}
$$

Here, $h=$ total height of the beam; $h_{t f}=$ heigth of the top flange; $h_{b f}=$ height of the bottom flange.

The total shear strength is then calculated by Equation 8 and Equation 9. The total shear comprises of two components, namely as concrete contribution and steel contribution (Figure 11 and Figure 12).

i.e total shear $V=V c+V s$

where,

$$
\begin{aligned}
V_{C} & =V_{c z}+V_{i y} \\
& =S_{c z} \times A_{c z}+S_{i} \times A_{i} \times \operatorname{Sin} \theta \\
& =S_{c z} \times y_{c o m} \times b+S_{i} \times l_{i} \times b \times \operatorname{Sin} \theta \\
& =S_{c z} \times y_{c o m} \times b+S_{i} \times Y_{c k} \times b \\
V_{S} & =V_{t f}+V_{w e b}+V_{b f} \\
& =S_{t f} \mathrm{~A}_{t f}+S_{w e b} A_{w e b}+S_{b f} A_{b f} \\
& =S_{t f} \times b_{t f} \times h_{t f}+S_{w e b} \times t_{w e b} \times h_{w e b} / \operatorname{Sin} \theta+S_{b f} \times b \times h_{b f}
\end{aligned}
$$

Where, $V_{c z}, V_{i y}, V_{t f}$, $V_{w e b}$ and $V_{b f}$ are shear force contributed by concrete compression zone, vertical interlocking, top flange, web and bottom flange respectively in $\mathrm{kN}$ and $A_{c z}, A_{i}, A_{t f}, A_{w e b}$, and $A_{b f}$ are their corresponding areas in $\mathrm{mm}^{2} ; l_{i}=$ length of the crack, $\mathrm{mm} ; b=$ width of the beam, $\mathrm{mm} ; t_{\text {web }}=$ thickness of the web, mm; $\theta=\left(\theta_{t}+\theta_{b}\right) / 2$ and $\leq 45^{\circ}$

All other parameters have their usual meaning stated earlier.

\section{Crack Configuration}

To know the exact geometry of the crack, additional parameters are needed (Figure 13). They are as follow:

- inclination at the top of the crack $\left(\theta_{t}\right)$

- inclination at the bottom of the $\operatorname{crack}\left(\theta_{b}\right)$

- $\quad$ radius of curvature of the crack $(R)$

- center of curvature of the crack $\left(C_{x}, C_{y}\right)$

- $\quad$ distance from loading point $\left(X_{\text {load }}\right)$

Angle $\theta_{b}$ and $\theta_{t}$ can be calculated by following Equation 10 and Equation 11.

$$
\begin{aligned}
& \theta_{b}=69 \log (a / d)+34 \text { and } \leq 90^{\circ} \\
& \theta_{t}=-40 \log (a / d)+51 \text { and } \geq 20^{\circ} \\
& \text { here, } \theta_{\mathrm{b}} \text { and } \theta_{\mathrm{t}} \text { are in degree. }
\end{aligned}
$$

After knowing $\theta_{t}$ and $\theta_{b}$, the radius of curvature of crack can be calculated by following Equation 12 .

$$
\begin{gathered}
R=K \frac{Y_{c k}}{\sin 45^{0}} \times \frac{180}{\pi\left(\theta_{b} \approx \theta_{t}\right)} \\
K=\frac{\text { arc length }}{\text { chord length }}=\frac{L_{\text {arc }}}{L_{c d}}=\frac{\left(\theta_{b} \approx \theta_{t}\right)}{2 \sin \left[\left(\theta_{b} \approx \theta_{t}\right) / 2\right]}
\end{gathered}
$$

The center of curvature of crack can be located by following Equation 13 and Equation 14.

$$
\begin{aligned}
C_{x} & =R \sin \theta_{b} \\
\mathrm{C}_{\mathrm{y}} & =R \cos \theta_{b}
\end{aligned}
$$




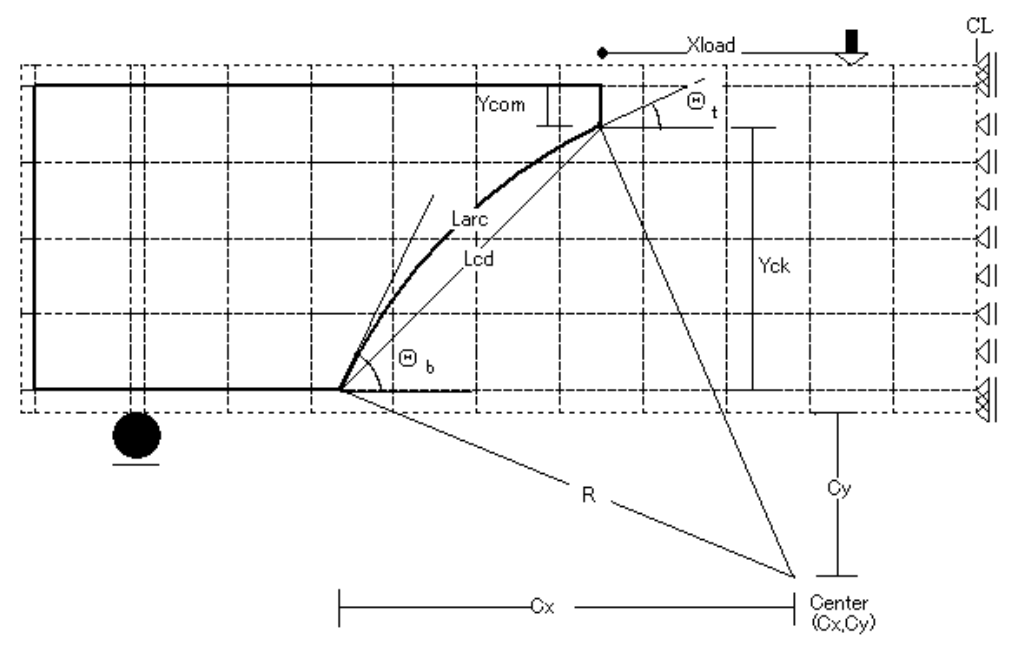

Figure13. Geometric parameters of critical crack

\section{Model Verification}

The proposed shear strength equations are then veri-fied for a lot of cases comprise of both experimental and analytical specimens. In both cases calculated shear strengths show quite a good agreement with that of the experimental and analytical one and fall within $\pm 5 \%$ bandwidth of each other, except a few, as shown in Figure 14.

The percent contribution to shear from FEM re-sult and from proposed shear strength equations are also shown in following Figure 15 and Figure 16 respectively for exeBN4 experimental specimen. They show almost similar contributions, especially in steel.

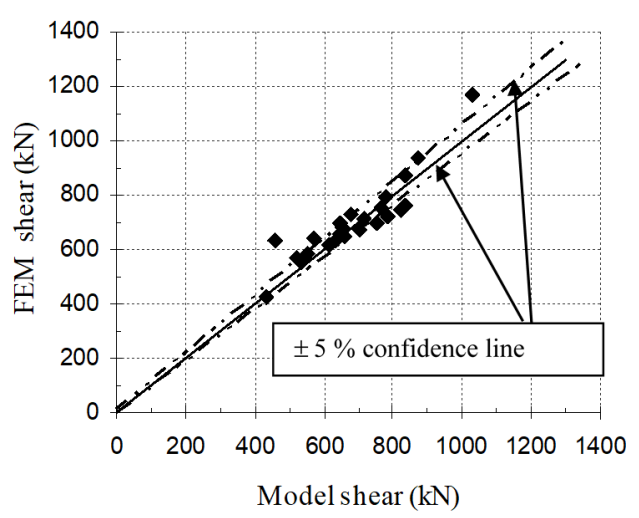

Figure 14. Comparison of shear strength

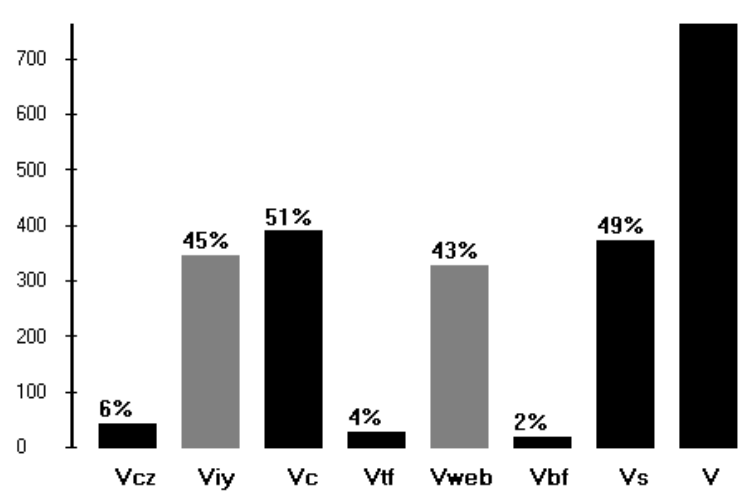

Figure 15. Shear contributions from FEM analysis

Another important point came out from this figures that among all those 5 components, aggregate interlocking stress in concrete and diagonal shear stress in web steel are the two major contributors to the total shear strength.

During the development of the aforementioned shear stress equations it was also observed that aggregate interlocking stress in highly influenced by $a / d$ ratio and percentage of web steel, $P_{w}$ (Figure 17 and Figure 18) whereas stress in web steel is influenced by all those five parameters mentioned in section 4. Among them, yield strength of web steel $f_{w y}$ (Figure 19) has a crucial role in addition to $a / d$ and $P_{w}$. 


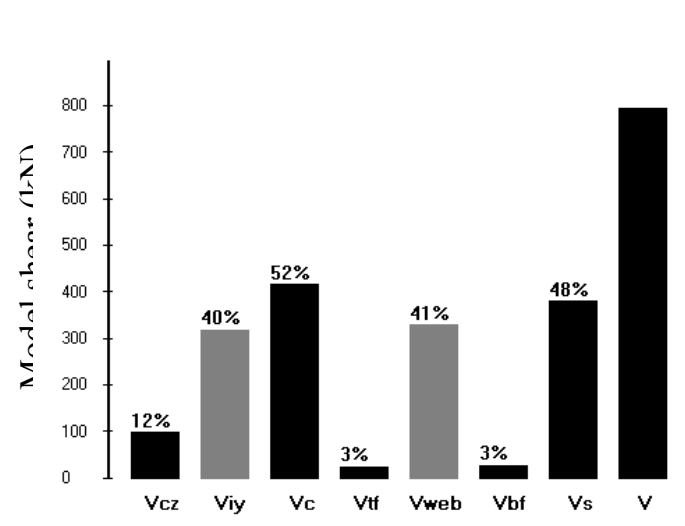

Figure 16. Shear contributions from model equations

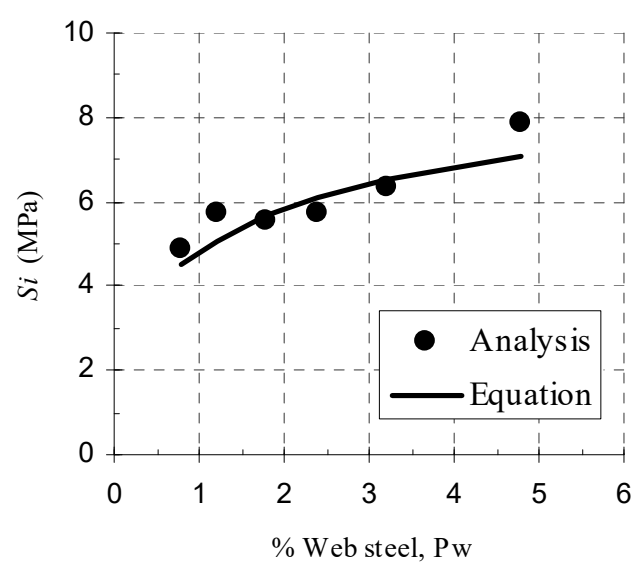

Figure 18. Variation of $S_{i}$ with $P_{w}$

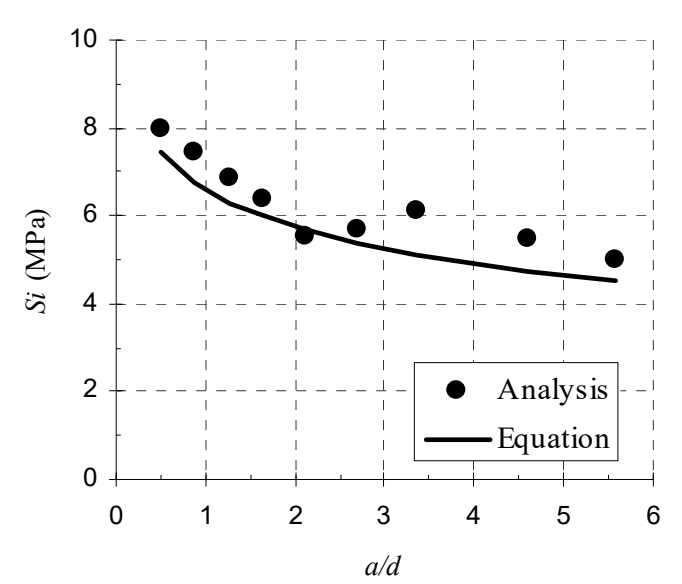

Figure 17. Variation of $S_{i}$ with $a / d$

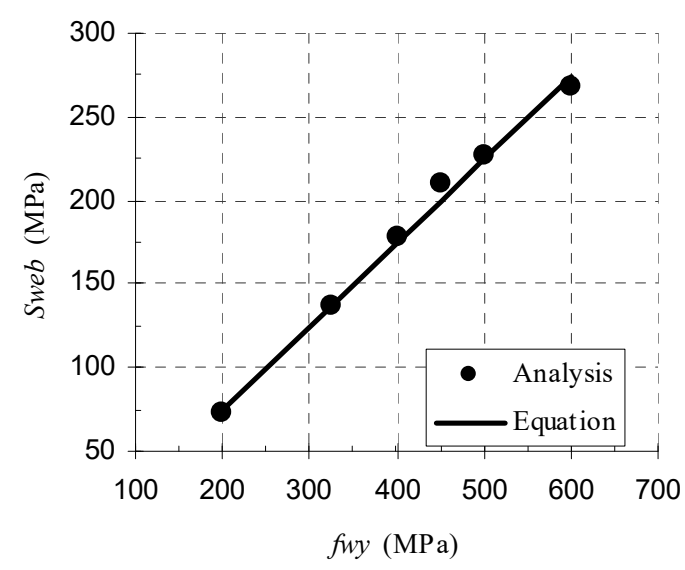

Figure 19. Variation of $S_{w e b}$ with $f_{w y}$

\section{Conclusions}

In this study a macro physical model for shear resisting mechanism has been proposed which is in some extent different from the model adopted by Ito, Ueda and Furuuchi (1999) but almost similar to Ueda, Nakai, Furuuchi, and Kakuta (1997) model. A horizontal cut plane, which connects the vertical compression zone and a diagonal cracking zone in Ito et al. (1999) model is eliminated in this proposed model that is because it has been assumed that the failure plane will trace a shorter distance to minimize the effective cross-sectional area and to maximize shear stress prior to failure. After all, this model is simple and selfexplanatory.

To avoid substantial overestimation or underestimation the ratio of internal resistance to external shear force $\left(V_{\text {int }} / V_{\text {ext }}\right)$ was always kept around 0.98 to 1.05 , which leaded the proposed equations to the present form of accuracy. That is way, though some other section showed a higher stress profile, was not considered as critical if its $V_{\text {int }} / V_{\text {ext }}$ does not fall within the stated limiting boundary.

Though there exist a difference between past and present shear resisting model, results are consistent between the two, which implies that starting may be different but destination is same. More over proposed shear strength equations will eliminate the limitations in the existing shear design equations drafted by JSCE (1992) for the first time and equations proposed by Ueda (1992).

To apply the proposed equations for beam loaded with other than concentrated load, some modification is needed to those equations, which is beyond the scope of this study.

For efficient design, a suitable safety factor or strength reduction factor can be applied to those equations or on calculated shear strength depending on the structural safety and importance. And this matter partially relies on efficient engineering judgment.

In this study the influence of shear connector (Saidi, Furuuchi \& Ueda, 1998) on shear strength is not considered to avoid any complicacy in the proposed equations. However a minimum amount of shear connector provided in 
JSCE (1992) design code or in any relevant design code is strongly recommended to avoid any discrepancy in shear strength.

End plate or sufficient amount of shear connectors must be provided at the both ends of the beam to avoid premature anchorage failure or secondary shear tension failure. The thickness of the end plate can be calculated from the necessary transferred force at anchorage.

\section{References}

Ito, T., Ueda, T., \& Furuuchi, H. (1999). Unified approach for-shear strength prediction of full and open steel-concrete sandwich members. Journal of Structural Engineering, JSCE. 40A, 1532-1542

JSCE Research committee on steel-concrete sandwich compos-ite structure. (1992). Design code for steel-concrete sandwich structures-draft. Concrete Library International, JSCE. 20, 1-21

Nares, P., \& Ueda, T. (1991). An analytical investigation of-sandwich beams in shear. Proceedings of The Third Interna-Tional Conference On Steel Concrete Composite Structures, 521-526.

Rahman, A., \& Ueda, T. (2002). Numerical simulation of shear resisting mechanism and shear strength equation for box and open sandwich beams. Master thesis submitted to Hokkaido University.

Saidi, T., Furuuchi, H., \& Ueda, T. (1998). Relationship between transferred shear force and relative displacement of shear connector in steel concrete sandwich beam. Journal of Structural Engineering, JSCE. $44 A, 1537-1545$

Ueda, T. (1992). Proposed shear strength equations for steel-concrete sandwich structures. Proceedings of Conference on Advance Composite Materials in Bridges And Structures, 669-678.

Ueda, T., Nakai, K., Furuuchi, H., \& Kakuta Y. (1997). Shear-strength prediction of steel-concrete sandwich beams. Proceedings of Conference on Composite Construction in Steel and Concrete, 119-128.

\section{Copyrights}

Copyright for this article is retained by the author(s), with first publication rights granted to the journal.

This is an open-access article distributed under the terms and conditions of the Creative Commons Attribution license (http://creativecommons.org/licenses/by/4.0/). 